Journal of Awareness

Cilt / Volume 5, Say1 / Issue 3, 2020, pp. 299-308

E - ISSN: 2149-6544

URL: https://journals.gen.tr/joa

DOİ: https://doi.org/10.26809/joa.5.022

Araştırma Makalesi / Research Article

\title{
CONSTRUCTING THE CONCEPT OF THE PHYSICAL INTERNET AS OPPOSED TO THE CONCEPT OF LOGISTICS WITH A VIEW TO ESTABLISHING THE PARADIGM OF SOCIETY-BUSINESS- TECHNOLOGY AS PART OF INDUSTRY 4.0
}

\author{
Naci Atalay DAVUTOĞLU * \\ * Lect., Erciyes University, Vocational School of Social Sciences, Management, \\ TURKEY, e-mail:davuta@erciyes.edu.tr \\ ORCID: https://orcid.org/0000-0003-4881-8242
}

Received: 30 April 2020; Accepted: 20 July 2020

\begin{abstract}
Concepts such as present-day mentality, human activities, technology, social and economic environments and organisational climate have had to undergo constant change following Industrial Revolutions. These changes in the management world have created a new value in production and service sectors. Supported by technology and device s that autonomously communicate with each other, these chains have ensured more modernized production processes. As the most recent trend, Industry 4.0 provides appropriate systems, physical attributes and diverse technologies that can cater for the future needs of economies by means of its initiation into business life with the motto of technological change and restructuring.

The present study aim stories awareness of the concept of the Physical Internet, which is believed to provide new solutions to the field of logistics, and is an open global logistic system that has re defined existing supply chain structures, as well as current business and value creating models. This concept provides privileges in terms of transporting abstract and concrete products of enter prises via internet all over the world, as well as storing and supplying them.

Consequently, the aim of the present study includes theoretically analysing the concept of the Physical Internet, which is one of the technological solutions provided by Industry 4.0, by means of literature review, which is defined as second-hand data, along with developing a different view point on enterprises' vision and knowledge, and ensuring that enterprises do not miss the opportunity to restructure themselves. For an enterprise to be powerful, it is required to seize on opportunities and employ them in internal dynamics. Hence, if enterprises aspire to create value chains in the in activities, they should primarily seize on opportunities with the help of Industry 4.0, which is considered to be the future industrial revolution, adapt them to their own structures, and, in turn, be new generation enterprises by raising awareness.

Concisely, the aim of the study is to bring a new perspective on logistic activities with the concept of the Physical Internet, ensure there vision of the current situation, and offer a solution to society-business-technology paradigm.
\end{abstract}

Keywords: Industry 4.0, Internet of Things, Internet of Services, Physical Logistics, Digitalization.

JEL Kodu: M10, M11, M12. 


\section{INTRODUCTION}

The keyword of the modern approach called Cyber Age is probably digitalisation. This concept dominates nearly all human and operating activities. As a concept of the future, digitalisation will acquire a significant position considering the outcomes of Industry 4.0, which is the vision of current managerial world, in conjunction with the process of human and operating activities together.

While the keywords of previous industrial revolutions were mechanisation, electrification, information and technology, the Fourth Industrial Revolution has introduced the concept of Digitalisation that refers to the essence of Cyber-Physical Systems into work and social organisation. As a result, this concept holds a significant position in the organisation and management of all value chain processes in production and service sectors.

As a component of Industry 4.0, digitalisation will consist of self-manufactured and selfcontrolling products and storage units with independent communication by means of ensuring the formation of global networks. Accordingly, improvements in design, production, distribution and usage will be inevitable. Each change in production and service concept will possess a multiplier effect in the transformation of the entire product, information and financial flows that represent logistics division.

Despite existing in all stages of logistics industry, the concept of logistics has undergone a change in accordance with the concept of Industry 4.0 in terms of both the forms of executing its main aim and the aim of operating activities via the Fourth Industrial Revolution. Thus, during the process of the development of industrial concept, the concept of logistics has to evolve owing to reasons like the increase in productivity, meeting the requirements of producers, a higher service mentality for customers as the current productivity level of logistics is not ideal, and logistics organisation requires a new concept in conjunction with Industry 4.0.

The Physical Internet can become the new organisational and administrational paradigm for logistics organisation. Introduced by Prof. Benoit Montreuil of Laval University in Quebec, Canada, the concept entails establishing logistics activities in an open and shared network, named the Physical Internet. Consequently, the concept is anticipated to present a practical solution for production and service sectors considering technological, social and business paradigms.

\section{THE CONCEPT AND SCOPE OF INDUSTRY 4.0}

Germany possesses one of the most competitive production industries as the global leader in production equipment sector. Thanks to this strength, the nation has improved its innovative production technologies, which, in turn, has ensured maintaining its leadership by means of providing constant expertise in areas, such as complex industrial processes. Its strong production industry has acquired leadership subsequent to developing its national strategy based on development in terms of the changes in global information technology, technological information structuring in Cyber-Physical Systems, and production and automation engineering. Consequently, the new industrialisation vision, namely Industry 4.0, has emerged in this country (Moment; 2014).

The first three industrial revolutions were the result of mechanisation, electrification and computerisation. Nowadays, the Fourth Industrial Revolution has transformed the Internet of Things and Services into production. In the future, businesses will modify and improve their technologies, logistics systems, and production facilities through forming global networks in the form of Cyber-Physical Systems. Hence, businesses will carry out information production, control function, smart machines and storage systems within the production environment independently thanks to Cyber-Physical Systems. Accordingly, concepts such as production, 
engineering, material procurement, supply chain, and life cycle systems will rapidly develop (Acatech; 2013). Figure 1 indicates the functional structure of Industry 4.0.

Figure 1. Functional Structure of Industry 4.0

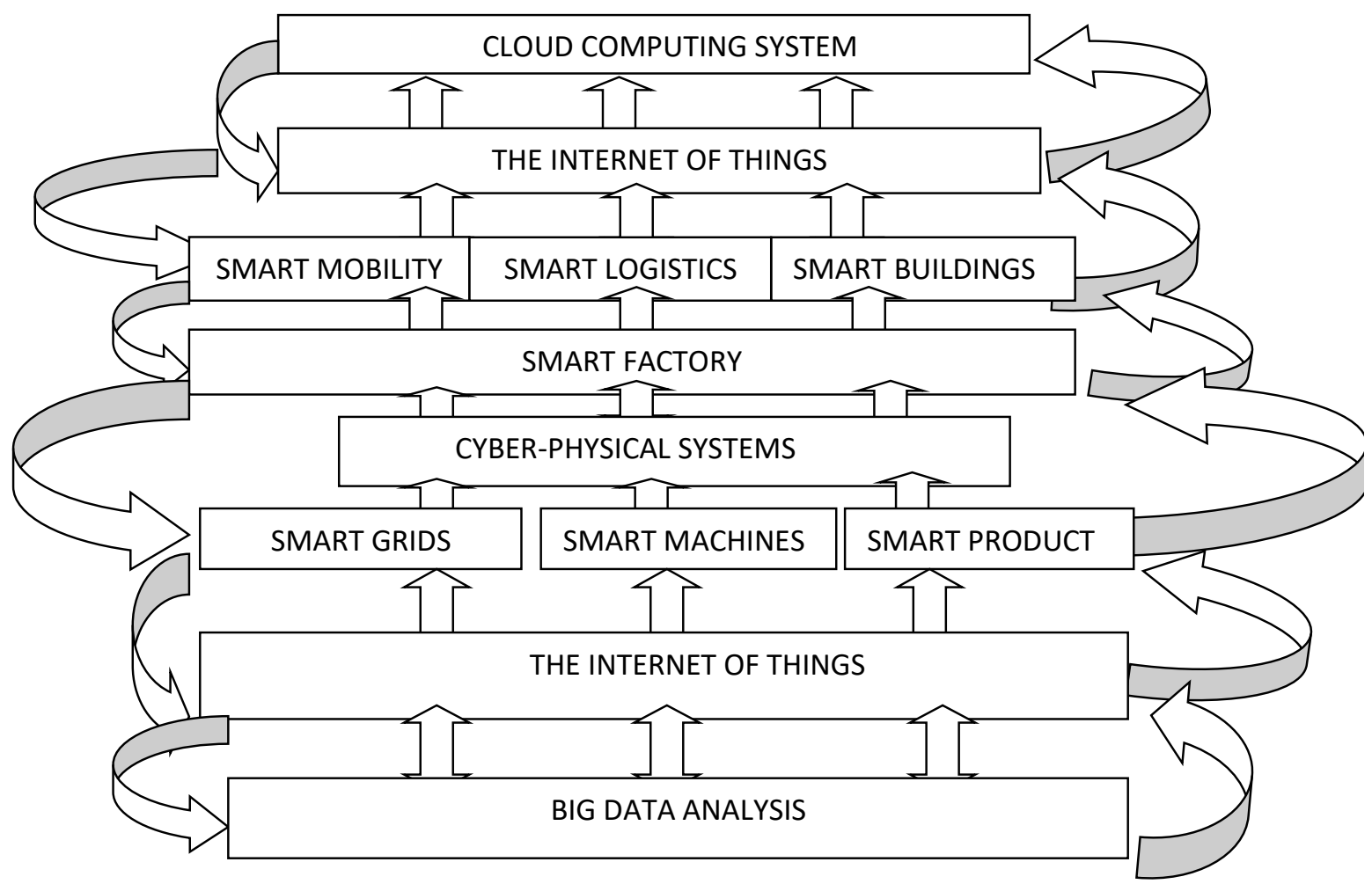

Source: Acatech (2013). National Academy of Science and Engineering, Recommendations for Implementing The Strategic Initiative Industrie 4.0.

Using robots with artificial intelligence in production, concepts like self-managing machines, products with information catalogues detailing their life stories, and customised smart personal products produced in smart factories formed subsequent to Industry 4.0 will add a completely new dimension to production. Additionally, smart products produced via this concept consist of uniquely defined and obtainable products that contain product stories and their current conditions, send information back to factories in case of a malfunction, and are equipped with alternative strategies to achieve targets (Bauerhan et al.; 2014).

Whereas Cyber-Physical Systems are vertically connected to businesses processes in factories and businesses, they are horizontally linked to each other through value networks, such as environment, customers, distribution channels, and logistics. This value chain is constructed end-to-end via engineering genius. Hence, Industry 4.0 entails a huge potential. Namely, smart factories constructed thanks to this system will boost the profitability potential of the production of each product, albeit individual, by means of enabling individual customer requirements to be met (Brettel et al.; 2014).

The dynamic business and engineering processes in Industry 4.0 consist of acquiring abilities, such as adapting to simultaneous changes in production, responding instantly to cuts and failures, and ensuring coordination between supply and logistics activities. Industry 4.0 grants end-to-end transparency in production, which, in turn, presents easiness in decisionmaking, significance of value networks, and ways to create new business models. Furthermore, it ensures new opportunities for businesses in terms of customer-oriented services. Industry 4.0 will also contribute to finding out solutions to common challenges today, such as productive 
and effective usage of resources, energy efficiency, urban production model, and demographic changes (Porter\&Heppelmann; 2015).

By means of ensuring sustainable development in production and services, Industry 4.0 will simultaneously grant resource efficiency and effectiveness of value networks. In order to achieve the desired outcomes, it is vital to organise carefully social factors, as well as demographic changes. Thanks to smart assistance systems, the concept of routine work will be eliminated, as employees will focus on creative and value-added activities. Accordingly, they could be more qualified and productive for longer periods of time; and, hence, will acquire a better work-life balance by means of improving their work, private lives, and career development thanks to flexible work organisations in businesses (Herman et al.; 2015).

Full adoption and implementation of the concept of Industry 4.0 is formed by the harmonisation of horizontal and vertical integrations. Vertical integration stands for harmonisation of entire internal systems of the business, and horizontal integration signifies harmonisation of all external systems of the business.

\section{CHARACTERÍSTICS OF INDUSTRY 4.0}

Industry 4.0 entails five concepts, which are ensuring socio-technical interaction in all production resources and processes, identification of unique smart products, providing customised production, enabling employees to control, organise and structure smart production resource networks, establishment of required agreements for the expansion of the Internet of Things and Services, and creating the infrastructure of network service quality (Acatech; 2013).

\subsection{Socio-technical Interactions in All Production Resources and Processes}

Socio-technical interaction in all production resources and processes of businesses within Industry 4.0 is implemented with the help of autonomous production networks, such as smart robots, conveyors and storage systems. This process addresses self-configuration, information based production, and self-operating, -assessing and -correcting system. As a significant component of socio-technical process, smart factories are integrated into value networks between businesses, and ensure constant monitoring and development of production processes, product quality, and digital environment. They will enable increasingly complex production processes to be managed with minimal labour, as well as operating with an awareness of social environment.

\subsection{Smart Products}

This concept stands for each smart product's ability to possess its own life story and manual, ways of usage, and its communication with the smart factory by means of built-in sensors. At the same time, the production of each smart and self-controlling product in smart factories is carried out by smart production, i.e., smart robots with artificial intelligence without human intervention. Moreover, smart products increase their economic lives by means of increasing the functionality of the product through self-optimisation, and directly communicating any wear and tear during their life cycle to the smart factory. The concept also integrates maintenance and operating practices via optimisation of logistics services, distribution channels, and supply chains for businesses.

\subsection{Customised Production}

The concept of Industry 4.0 grants the gradual emergence of topics, such as individual features, design and structuring of customers and products, types of order, time planning, types of production, and feedback. Not only the production of a customised product but also a small amount of production will be optimised and carried out by means of making changes in any one of these stages immediately before or after the production. 


\subsection{Enabling Employees to Control, Organise, and Structure Smart Production Resource Networks}

This concept signifies the control of smart production resource networks that rely on targets sensitive to the conditions and features of the employees, and structuring production networks. Through this concept, it is aimed to enable employees to focus on creative activities with high added value, and to increase service quality. Accordingly, as well as bringing about flexible working conditions, this concept facilitates efficient employees.

\subsection{Establishment of Required Agreements for the Expansion of the Internet of Things and Services, and Creating the Infrastructure of Network Service Quality}

By means of making value-added network agreements with the required institutions and organisations to increase the quality of the Internet of Things and Services, and setting up the infrastructure for broad-based internet network, the concept aims to boost the features of service quality. Meanwhile, the concept allows for Cloud Computing and Big Data Analysis in order to increase the speed of intensive data applications, along with addressing the needs of businesses with broadband applications.

\section{THE SCOPE OF LOGISTICS}

The concept of logistics signifies the activities that assist the management of every kind of product, information, material, and money flow within the process from production to consumer. Namely, it entails implementation of certain concepts, such as controlling delivery, storage and distribution (Taylor; 2008). The introduction of the concepts, such as globalisation, technological improvement, the internet, and virtual organisations into daily life, and their rapid expansion, as well as the constant improvement of transportation infrastructure, and creating new combinations for types of transportation have all enabled effective fulfilment of logistics activities.

The concept of logistics possesses a wide spectrum of application areas in terms of contend, consisting of engineering, accounting, human resources, marketing, R\&D studies, public relations, sales techniques, and advertisements (Rushton et al.; 2007). It basically aims to supply the right product for the right customer at the right amount, in the right condition, place and time, and with the right cost (Çancı\&Erdal; 2003). Additionally, it intends to achieve these goals with the lowest cost, minimal mistakes and highest quality in the fastest way possible.

In order for businesses under the influence of globalisation and rapid improvement in technology to survive in a competitive environment, they need to be endowed with three basic features, i.e., velocity, flexibility and cost advantage. With the rapid improvement of logistics consequent to these advantages, businesses have begun to change the ways of conducting business. Dominance in local markets is no longer adequate, and logistics have globally gained prominence in terms of penetrating into new markets and dominating them.

In a rapidly developing and changing competitive environment, businesses have to increase their market share, survive and compete with others. Nowadays, customers have a more increased awareness, and demand the delivery of customised products in a suitable quantity and speed. Yet, surges in the global and national economy pose major risks to businesses. Accordingly, businesses have begun implementing fundamental changes in their management and production structures. With digitalisation, which is also called the Fourth Industrial Revolution, it is inevitable for logistics services to undergo a structural change in order to adapt to changes and variables, be less affected by fluctuations, and rapidly benefit from the up-to-date information communication technologies and knowledge. 


\section{THE CONCEPT AND SCOPE OF LOGISTICS TRANSFORMATION}

One of the basic prerequisites of Industry 4.0 is digital transformation. Digitalisation signifies the technological transformation of businesses along the value chain with the help of the synergy it created in order to be successful in business and social environment (Smit et al.; 2016). In order to carry out logistics transformation along with technological change, businesses need to consider certain concepts, such as developing their digital abilities, providing cooperation in the ecosystem, managing data as a commodity to secure major control points, establishing cyber security systems, and implementing a data architecture based on Industry 4.0 (Andrejiová et al.; 2012). The logistics transformation businesses undergo via Industry 4.0 provides precedence in terms of growth on physical and operational basis, competitiveness, and generating investment and employment. Hence, employing digital technology in businesses should be a primary duty and an encompassing policy for all sectors in the economy (Founou; 2012).

The scope of Industry 4.0 entails plenty of data and digital opportunities that can increase the utilisation of current resources in logistics sector. Businesses carry out their logistics transformation with the help of smart logistics by means of increasing the ability to analyse, communicate, design, comprehend and optimise as a result of increasing effective usage of these data and opportunities (Stojanovic ; 2012).

In traditional logistics systems, time and price (cost) constitute the parameters of logistics services. However, in addition to these parameters, the multiplier effect of digitalisation as a result of concepts such as globalisation, environmental conservation, energy efficiency, and increasing competitive pressure need to be embraced as a distinct parameter in the refurbished production and services sectors that have been restructured in accordance with Industry 4.0 (Fedorko et al.; 2010). Thus, logistics transformation contains changing the product context of logistics activities in accordance with the end user. The change in this context also explains the change in logistics processes that are based on digitalisation.

Consequently, the most significant benefit of logistics transformation is creating a society-business-technology paradigm in planning, organising, structuring, and managing Physical Logistics processes.

\section{THE CONCEPT AND SCOPE OF THE PHYSICAL INTERNET}

The Physical Internet (PI) was introduced as a concept by Prof. Benoit Montreuil of Laval University in Quebec, Canada (Marinko et al.; 2016). Nowadays, the concept is examined at universities all over the world, such as UQAM (Université du Québec à Montréal), MINES Paris Tech, Georgia Tech, Atlanta, and Virginia Tech, and a public website, http://physicalinternetinitiative.org, was created (Marinko et al.; 2016).

This concept was inspired by the mobile transfer of the metaphor of Digital Internet, which includes storage, management, realization, supply, and usage of products. This system is structured based on The Physical Internet Manifesto and The Physical Internet Foundations (Montreuil et al.; 2011).

The Physical Internet stands for an effective, sustainable, resilient, applicable, stable, and interconnected logistics network. It is a flexible open global logistics system founded on physical, digital and operational interconnectivity through encapsulation, interfaces and protocols (Barbarino; 2015). The Logistics Web Network is equipped with new containers, new supply chain interfaces, i.e., logistics centres, such as nodes, hubs, stores, and distribution, along with new transportation and storage technologies, such as movers and conveyors, and integrated logistics networks. The most widespread attribute of this network is its openness or free use (Ballot et al.; 2011). 
The Physical Internet establishes a complete cooperation among all participants in the supply chain, and ensures an utter coordination of all applied technique-technological resources and solutions (Montreui; 2011). All operations in this network are carried out in accordance with the principle of optimality. In other words, Physical Logistics signifies open global mobility as well as mobility within supply chains, carrying out the transformation of logistics operations to efficient and universal interconnections, and ensuring communications with all logistics networks (Landschutzer et al.; 2015). In this system, the key to establish a universal connection is comprised of digital connections, modular load units, interfaces (physical connectivity), and protocols and procedures (operative connection) (Sallez; 2015). Figure 2 indicates this concept (Montreui; 2012).

Figure 2. The Concept of Physical Internet and Physical Connectivity

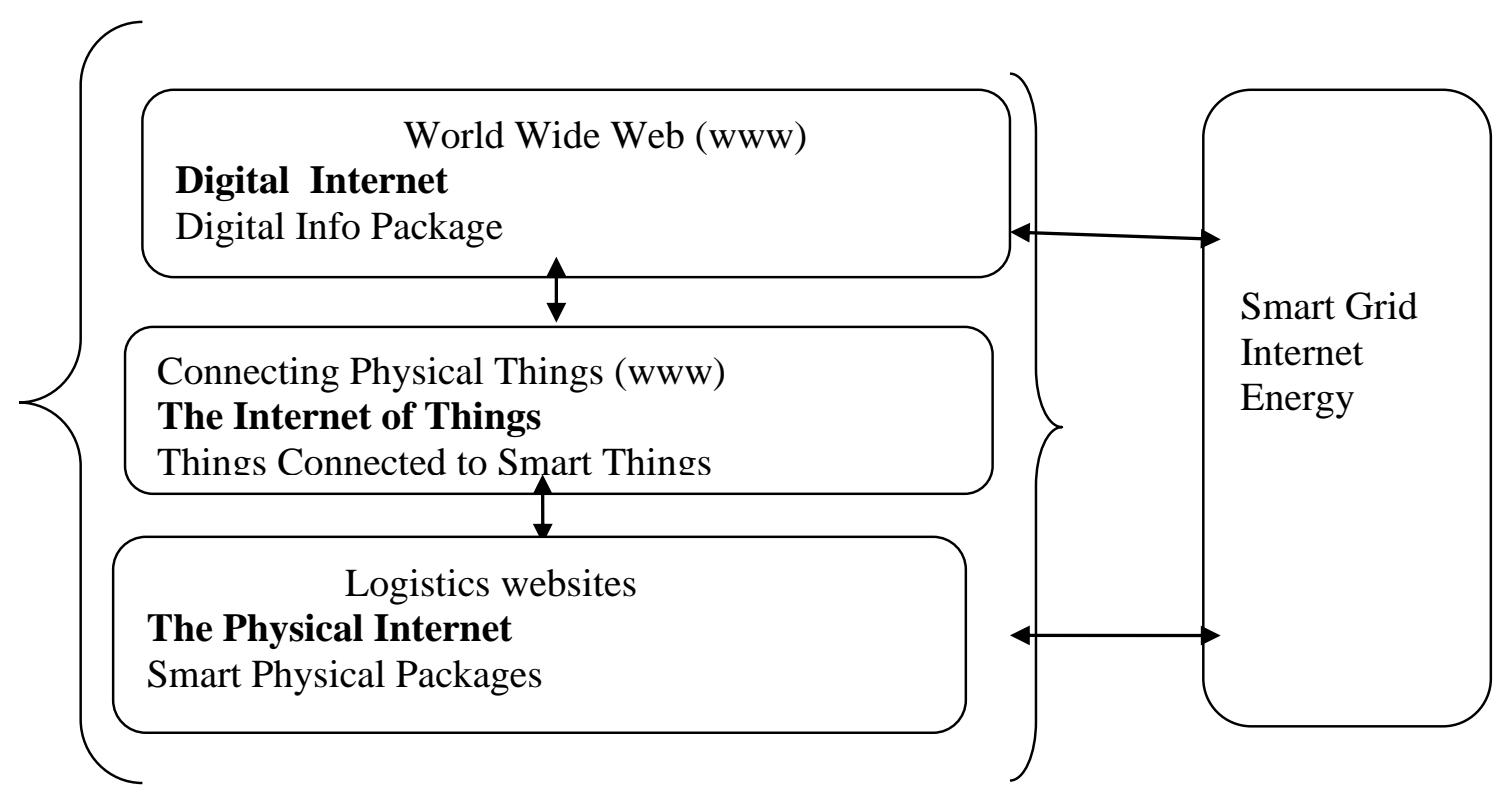

Source: Montreuil, B. (2012). Physical Internet Manifesto, version 1.11. 1. CIRRELT Interuniversity Research Centre on Enterprise Networks, Logistics and Transportation.

In the Web Network system, physical connection is carried out with the concept of "Smart Grids". Through this network, smart load and storage capacities are determined and suitable modular units (containers) are formed. These load units accomplish logistics services by means of establishing digital connections and communication with each other, and optimum matching with transfer sources in the logistics centres called hubs (Montreui; 2012).

Therefore, digital connectivity ensures effective communication by ensuring the connection of products and services with world-class smart grids. Utilizing protocols and procedures for planning, realizing, and managing load flows of modular units with the operative connection is also carried out through this system (Montreuil et al.; 2011). Hence, Physical Logistics optimise embedded smart objects with the help of global descriptive smart tags with the Internet and World Wide Web, and effective usage of the abilities of smart containers (Montreuil et al.; 2011).

The system of smart tags grants an effective interaction of the containers they are embedded in and the operations of other systems, such as movers and hubs. Accordingly, Physical Logistics System for businesses signifies a visionary viewpoint that calls on major technological changes. This is achieved gradually, yet with the logic of the big-bang theory (Montreui; 2012). 


\section{CONCLUSION AND DISCUSSION}

While Industry 4.0 transforms businesses irreversibly, it overwhelmingly influences and changes traditional business models. Nowadays, businesses need to embrace the first condition of competition, i.e., the rate of transformation, and establish a successful business profile by ensuring the emergence of leaders in this transformation. Namely, acquiring leadership well ahead of others by means of integrating all of their processes and, thus, speeding up the transformation can only be achieved through promptly keeping up with the new industrial revolution. Through this transformation, businesses have to produce customised products and solutions to make an impression in the sector, increase customer loyalty, and better respond to needs and expectations. In order for the businesses impacted by globalisation and rapid development in technology to survive in a competitive environment, they require velocity, flexibility and cost advantage. The development of logistics as a result of these advantages, businesses have begun to change the ways of conducting business, since dominance in local markets is no longer adequate. Accordingly, logistics have globally gained prominence in terms of penetrating into new markets and dominating them.

Despite its existence in all stages of industry, the ways of operation and main aim of logistics have also transformed in accordance with Industry 4.0. Therefore, while the concept of industry is in the process of development, it is obligatory for the concept of logistics to develop due to the reasons, such as productivity growth, meeting the requirements of producers, and a higher service quality for customers. As the current logistics efficiency is not ideal, logistics organisation requires a new model in line with Industry 4.0.

The main aim of the study is to link the concept of the Physical Internet, which is a novelty in logistics, to Industry 4.0 and, thereby raise awareness, and bring about extensive studies considering this issue. The novel concept of the Physical Internet and the emerging trend Industry 4.0 have both given rise to new concepts such as business restructuring and strategy examples, data transport, cyber security, new technologic standards, the Internet of Things and Services, smart logistics, and smart grids.

The scope of Industry 4.0 entails plenty of data and digital opportunities that can increase the utilisation of current resources in logistics sector. Businesses carry out their logistics transformation with the help of smart logistics by means of increasing the ability to analyse, communicate, design, comprehend and optimise as a result of increasing effective usage of these data and opportunities.

Smart Logistics endows the new concept of logistics organisation with a new perspective via associating it with the Physical Internet. The Physical Internet, which possesses a vital position in the establishment of logistics organisation, links concepts such as loading units, moving and transportation units, digitalisation, and communication to smart grids.

Both Industry 4.0 and the Physical Internet are composed of the integrity of complex systems that signify major technological and commercial environmental changes. These concepts will actually ensure the establishment of global networks, and contain self- producing and self-controlling product and storage facilities. Hence, development in design, distribution and usage areas will be inevitable. Each change in production and service concepts will entail a multiplying effect in the transformation of all product, information and financial flows, all of which represent logistics. 


\section{RESOURCES}

Acatech. (2013). National Acedemy Of Science and Engineering, Recommendations For Implementing The Strategic Initiative Industrie4.0, Germany, April.

ANDREJIOVÁ, M., PAVLISKOVÁ, A., \&HUSÁKOVÁ, N. (2012). Application of multicriterion decision methods by the selection of optimal constructive elements for devices of continuous transport. CarpathianLogist. Congr., TANGER LTD. Ostrava, 16.

BALlOT, E., GOBET, O., \&MONTREUIL, B. (2012). Physical internet enabled open hub network design for distributed networked operations. In Service orientation in holonic and multi-agent manufacturing control (pp. 279-292). Springer Berlin Heidelberg.

BARBARINO S., (2015). A new concept for logistics: a Physical Internet, Presentation at GS1 Transport \&Logistics Workshop (12-13 October 2015, Warsaw, Poland).

BAUERNHANSL, T., TEN HOMPEL, M., \&VOGEL-HEUSER, B. (Eds.). (2014). Industrie 4.0 in Produktion, Automatisierung und Logistik: Anwendung, Technologien und Migration (pp. 1-648). Wiesbaden: Springer Vieweg.

BRETTEL, M., FRIEDERICHSEN, N., KELLER, M., \&Rosenberg, M. (2014). How virtualization, decentralization and network building change the manufacturing landscape: An industry 4.0 perspective. International Journal of Mechanical, Industrial Science and Engineering, 8(1), 37-44.

ÇANCI, M., \& ERDAL, M. (2003). Logistics Management, Freight Forwarder Manual 1. UTIKAD Publishing, Istanbul.

FEDORKO, G., HUSAKOVA, N., \&DUDAS, G. (2010). Design of allocation of new technological equipment within the frame of production process in company Getrag Ford Transmissions Slovakia, sro. Acta Montanistica Slovaca, 15, 14-22.

FOUNOU, R. (2002). The Role of IT in Logistics, Competitive Advantage or Strategic Necessity?. In 2nd Swiss Transport Research Conference (pp. 1-21).

HERMAN, M., PENTEK, T., \&OTTO, B. (2015). Design principles for Industry 4.0 Scenario: A literature review.

LANDSCHÜTZER, C., EHRENTRAUT, F., \&JODIN, D. (2015). Containers for the Physical Internet: requirements and engineering design related to FMCG logistics. LogisticsResearch, 8(1), 8.

MASLARIĆ, M., NIKOLIČIĆ, S., \&MIRČETIĆ, D. (2016). Logistics response to the industry 4.0: the physical internet. Open Engineering, 6(1).

Momnet. (2014). Germany and Industry 4.0 Hacettepe University Faculty of Communication Journal of Cultural Studies. April, 2014.

MONTREUIL, B. (2012). Physical Internet Manifesto, version 1.11. 1. CIRRELT InteruniversityResearch Center on Enterprise Networks, Logistics and Transportation.

MONTREUIL, B. (2011). Toward a Physical Internet: meeting the global logistics sustainability grandchallenge. Logistics Research, 3(2-3), 71-87.

PORTER, M. E., \&HEPPELMANN, J. E. (2014). WiesmarteProdukte den Wettbewerbverändern. Harvard Business Manager, 12(2014), 34-60.

RUSHTON, A. (2007). International logistics and supply chain outsourcing: from local to global. Kogan Page Publishers. 
SALLEZ, Y., MONTREUIL, B., \&BALLOT, E. (2015). On the activeness of physical internet containers. In Service Orientation in Holonic and Multi-agent Manufacturing (pp. 259269). Springer International Publishing.

SMIT, J., KREUTZER, S., MOELLER, C., \&CARLBERG, M. (2016). Industry 4.0. Study for the ITRE Committee, Policy Department A: Economic and Scientific Policy, European Parliament, Brussels.

STOJANOVIĆ, Đ. (2012). Paradoxes and opportunities in logistic outsourcing research. PROMET-Traffic\&Transportation, 24(6), 525-533.

TAYLOR, G. D. (Ed.). (2008). Introduction to logistics engineering. CRC Press. 